Car. Most infelicities come at the level of the sentence. Durcan has a tendency to over-elaborate, as when he points the reader toward Stalin and invites him to "notice how the upper lip curls, exposing the crown of a bicuspid, its glistening tip like an inverted Matterhorn the depth of an iceberg in the Barents Sea." Either the Matterhorn or iceberg simile would have sufficed; the two together are ungainly.

This tendency extends beyond the use of compound metaphors. Durcan's prose falters because of over-elaboration when he describes a Moscow official as follows:

The senior official, head visible in my mirror, now tilts his head back ever so slightly, not suppressing his smile: a cracked incisor is visible, the work of a father's hand or the tools of one of my colleagues, either wielded in infamy.

That latter phrase (my italics) is bizarre, needless and compromises the whole description. Yet all of this can be for-

\title{
My first Tensilon test
}

He came in with a few pages printed out from the Internet and started talking even before he had sat down.

"I feel tired all the time, but especially in the evenings. And my face has gone droopy. I looked it up on the Internet - I think it might be myasthenia gravis. I think I need to have a test called the Tensilon test. Am I right?"

My initial thought was that this patient had Internet Print-out Syndrome. But the history did reveal symptoms typical of myasthenia. The physical examination was also convincing: he tired quickly with exercise, and even though he spoke in short bursts, his voice faded toward the end of them. So I phoned the pharmacy to get some edrophonium.

As we were waiting, I explained to the patient what the test was all about. I explained that edrophonium - Tensilon - was used to diagnose myasthenia gravis and that patients with the disease improve after administration of the drug. I also explained the cholinergic side-effects, such as abdominal cramping and diarrhea. I put in an iv, attached the patient to a cardiac monitor and put some intravenous atropine on top of the resuscitation trolley. I had read up on the test recently and was ready for all eventualities.

I called in the other junior doctors and the medical students and slowly injected the placebo: nothing happened. Then I pushed in the Tensilon: the response was dramatic. My patient's face lit up, and his eyes opened wide. Then he started to cry. The hairs stood up on the back of my neck and I could feel my eyes fill up, too. Was this my first brilliant diagnosis as a neurology trainee? I called my boss into the room.

"Prof, his facial muscles improved dramatically — it was incredible — he even started to cry."

His dry response:

"You are probably right in your diagnosis. But don't get too excited about the tears. Lacrimation is an invariable response to the cholinergic stimulation of the tear glands."

All our hearts sank, and even the patient was looking more glum. Or maybe it was just the Tensilon wearing off.

\section{Kieran Walsh}

Editorial Registrar

$B M J$ Learning

BMJ Publications

London, UK

given as the trademark intrusiveness of the first-time author who runs around, trying to batten down each hatch, safely securing everything because he doesn't trust the reader.

On a related point, it is apparent that Durcan is at his best when he is obsessional, when there are just two main characters, and when the fictional world is circumscribed, as in the case of Stalin's mouth or the catastrophic father-son car ride to the hospital. When things get more complicated, Durcan juggles his variables less competently. Characters become two-dimensional, as in the drug-study story "Control," where there's a young punk, a thirtysomething neurotic, an old bearded guy and two Asian sisters - none of whom are developed beyond that. Durcan's fictional gaze is winningly myopic; he has not yet developed the talent of panorama.

Most concerning of all is an unfortunate tendency to rely upon stock metaphor; Stalin's moustache is described as a "brush," fear under Stalin's regime as a "cold front," an car engine howls "like a hungry wolf." Eyes have an "inner fire" as they "threaten to burst from their sockets." Worse still, a woman can arrive "as spring does, quietly infusing warmth and hope, inducing tender feelings in me that I have never known."

More often, though, Durcan's powers of metaphor acquit themselves well, such as when the dentist looks into Stalin's carious mouth and through the sense of smell likens it to a "wet cement floor, a room in the basement of Nikevsky Police Station, a drain at the centre of that floor that I have heard has seen everything pass." Chilling, and thus effective.

Yes, effective. That's how I describe A Short fourney by Car overall, a little paperback book that knows where it must go, and go quickly. Despite a few detours, it gets there. And although a canny neurologist is driving the car, you'd almost never know it.

Shane Neilson

Family Physician

Guelph, Ont. 